\title{
Finite Element Analysis of Cross Member Bracket of Truck Chassis
}

\author{
Balbirsingh R. Guron ${ }^{1}$, Dr. D.V. Bhope ${ }^{2}$, Prof. Y. L. Yenarkar ${ }^{3}$ \\ ${ }^{1}$ Student Department of Mechanical Engineering Rajiv Gandhi College of Engineering Research and \\ Technology, Chandrapur (Mah.) India \\ ${ }^{2}$ Professor and Head Department of Mechanical Engineering Rajiv Gandhi College of Engineering Research \\ and Technology, Chandrapur (Mah.) India \\ ${ }^{3}$ Assistant Professor Department of Mechanical Engineering Rajiv Gandhi College of Engineering Research and \\ Technology, Chandrapur (Mah.) India
}

\begin{abstract}
The component bracket in the cross member of chassis is one the most important parts of heavy trucks. Chassis has steel sections, longitudinal ones throughout the length of the vehicle and joined together by transverse parts called the cross members. Rear ones bear payloads and the front one has to bear the engine and transmission. For suspension, handling , body alignment, etc. they need to be strong , besides being complicated, costly and time consuming to replace, if damaged. Stresses induced lead to the failure of the component brackets in the cross members. This study aims to investigate the critical points of stresses that lead to or induce failure. To analyze, finite element method (FEM) is used \& commercially available packages MSC/NASTRAN with PATRAN are used for modeling and stress analysis. Modifications have been made to current bracket $\&$ these modifications have resulted in reduction in stress values leading to safe design .
\end{abstract}

Key Words: Cross Member Bracket, Truck Chassis, Finite Element Analysis

\section{INTRODUCTION}

One critical failure is that of a cross member bracket in the heavy truck chassis. Handling freight by trucks is an huge industry. The chassis in the truck is the structural mainframe. The chassis frame configuration in a truck till today is designed on conventional lines. It has two main longitudinal members throughout the length of the truck and has six or so cross members supporting the two longitudinal members and are riveted in place. The cross section is tubular, channel or double channel type. For cars and lighter vehicles other types are available. The two longitudinal sections of the chassis are robust enough to carry the main payload.

\subsection{The Problem Scope and Methodology}

In earlier models of trucks, the cross members were of single piece design and now comes as a multicomponent part. The cross member component nearest to the chassis (bracket) has to bear the brunt of all the loading and ultimately develops fractures starting at the rivet holes. This implies that, though the rivets hold the part well, the load ultimately leads to development of cracks in the member.

In routine run and loading, the cross member fails, as the chassis tends to flab in the central portion. This problem is solved by putting extra clamps over the chassis frame externally, before bringing the new vehicle on the road. Dampers provided by the truck manufacturer are removed off once the truck is in the field, for ease in the regular repair work, and because of increase in leaves in leaf spring set for overloading. The problem is compounded in the absence of the dampers in the suspension. Effective damping means less wear and tear of tyres, suspension components, and considerably lesser stresses in the chassis components. The damper provides additional cushioning which is very important. The damper support to absorb the extra load or impact is needed.

The front cross member under the engine rear is the most stressed and failure prone. It facilitates in proper handling, performance, effectiveness of the suspension and keeping the mountings and body panels etc. in alignment. It has to be strong enough not to yield due to the loads. It has to also resist torsional and bending loads.

Observation, questionairring and survey of fleets revealed that, this bracket situated nearest to the chassis mainframe is the biggest downtime contributor \& the failure of the bracket is observed at the rivet holes. The location of the bracket is shown in figs 1.1.

The actual photograph of cross member bracket is shown in figure 1.2. The components of the multi piece cross member are shown in figs 1.3 and 1.4. Fig 1.5 shows the actual fracture lines on the failed bracket. This cross member has limitations to design as space for movement for repairs, mounting and dismounting and accessories needs to be accommodated. 
The aim is to identify the cause of failure of the cross member bracket and to suggest design changes. The failure analysis of the cross member bracket is effected by design and analysis approach. The failure analysis has been carried out using using standard FE tools.

\subsubsection{Details of the Bracket}

Each bracket is attached to the longitudinal member of the chassis. The other cross member components on which the engine is mounted, is attached to flange of the bracket with six rivets. The height of the flange is $82 \mathrm{~mm}$ from the fixed central portion of the bracket plate which is fixed with the chassis. The thickness of the bracket plate is $6 \mathrm{~mm}$. The overall dead load of about 0.5 tonne of engine acts on the two cross members which is mounted on the truck chassis frame. This load is then distributed by the cross member over each bracket.
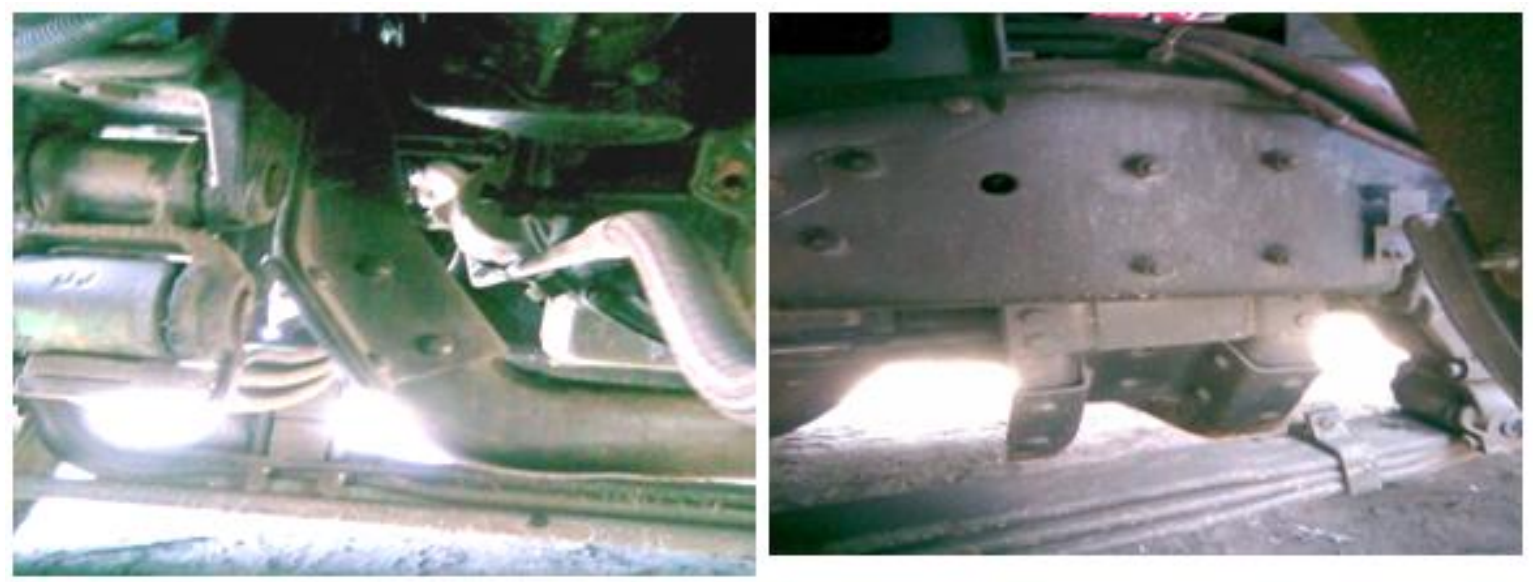

Fig. 1.1 Location of cross member bracket in truck

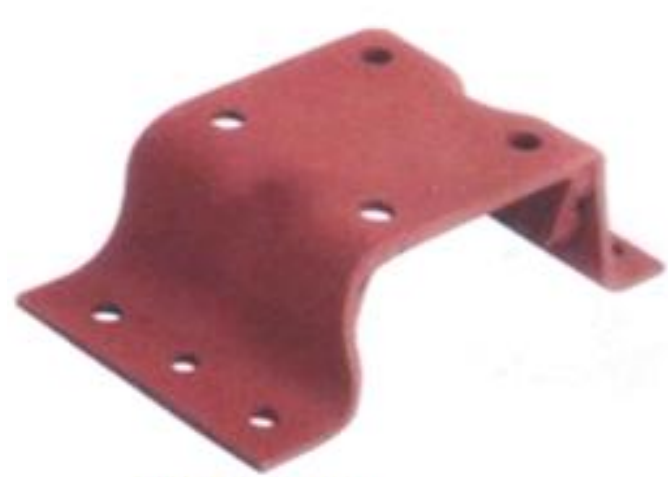

Fig.1.2 Bracket

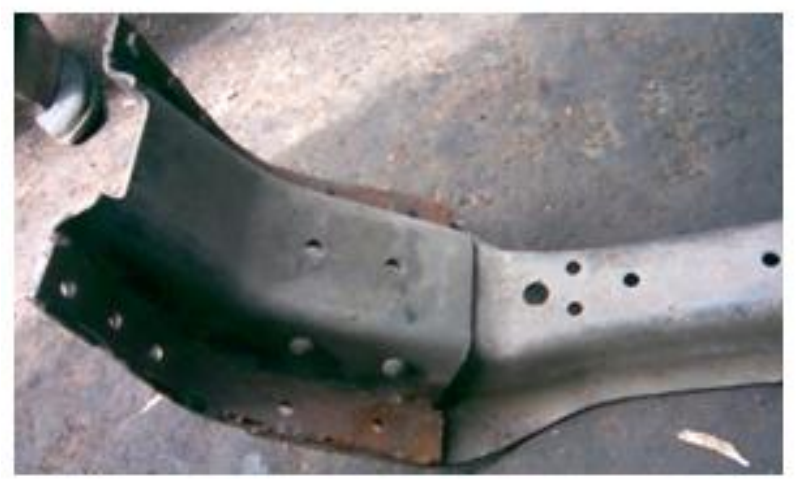

Fig. 1.4 Central component

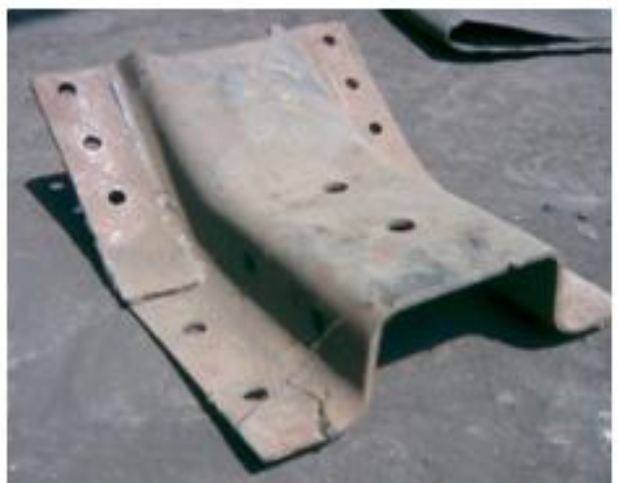

Fig.1.3 Intermediate component

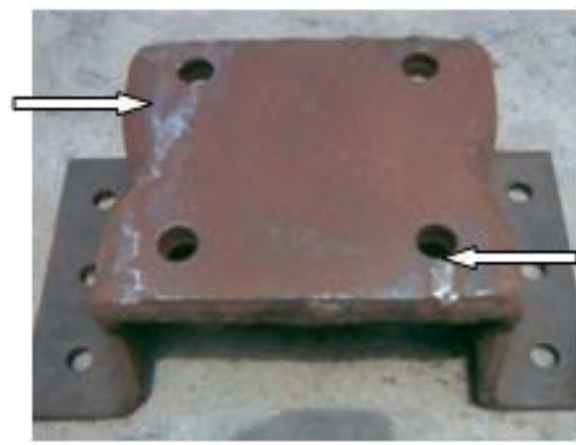

Fig. 1,5. Failure points in the bracket 


\section{LOAD ANALYSIS}

As the cross member is used as a support member, the bracket is loaded onty vertically along its width. The bracket takes the load only in the direction of its width and in the outer end portion, with the rivets holding the central face fixed in place attached to the longitudinal member of the truck chassis.

The gyroscopic couple is generated as the flywheel precesses when the truck moves with the noted speed of $60 \mathrm{~km} / \mathrm{hr}$ and exerts a load on each bracket. The load due to the centrifugal force acts on the cross member and thus is divided on each bracket when the truck is on turnings. Also the propeller shaft torque is acted over engine rear cross member brackets . These loads are distributed on each component bracket. It is observed that the maximum load is coming over the bracket at the engine rear end.

The summary of loads on bracket is shown in table 2.1. It is seen that the bracket is also subjected to an additional force. This could be confirmed from the survey of truckers' experience. This is be due to the payload acting laterally tending to flab the chassis in the middle or tensile pull due to insufficient or malfunctioning chassis grips, apart from the Load Case-I, II and III. But it is not possible to estimate this complex load due to chassis flab and not considered in the present analysis.

Table 2.1: Load on Cross Member Bracket

\begin{tabular}{|c|l|c|c|}
\hline Load Case & \multicolumn{1}{|c|}{ Particulars } & Force & Magnitude N \\
\hline I & Propeller shaft & $F_{1}$ & 7457 \\
\hline II & Centrifugal force & $F_{2}$ & 70 \\
\hline III & Gyroscopic couple & $F_{3}$ & 41 \\
\hline IV & Static engine weight & $F_{4}$ & 1230 \\
\hline \multicolumn{4}{|c|}{ Total Load } \\
\hline
\end{tabular}

\section{MODELING AND FE ANALYSIS OF BRACKET}

PATRAN FE Pre-post processor is used to model the cross member bracket and included the part modeling environment in which the extrude command is used for the modeling of the bracket and the stiffeners are made using the glide command. The parameters required for the modeling of bracket are contour dimensions height, length, fillet radius, hole diameter. Holes were made using surface trim command. The 3D SOLID is prepared by thickness in the third dimension provided after selecting the 2-D shell element.

The bracket model geometry is imported in NASTRAN. In design simulation quadra paver element is used for meshing of bracket. Equivalence of the nodes is executed for this element. PATRAN has a quadratic displacement behavior and is well suited to modeling irregular meshes. Figure 3.1 shows the modeling of the basic bracket. For the meshing of the cross member bracket with and without stiffeners the above described nodal quadra element is used with fine meshing. The material properties like modulus of elasticity and poisons ratio is assigned to the bracket in materials list in PATRAN. The modulus of elasticity and poisson's ratio for the steel_SI_mm material is $200 \times 103 \mathrm{~N} / \mathrm{mm}^{2}$ and 0.3.FE analysis has been carried out in MD NASTRAN. The analysis was carried out for the load calculated. At first the bracket is analyzed by considering the load calculated. The deflection and maximum shear stresses are obtained which will give comparative results for modifications in the bracket.

3.1 Boundary constraints for bracket, Models, Von-mises stress contours for various modifications of bracket

The bracket is fixed at central face of the plate and load is applied on the side ends of the flange of the bracket plate vertically. For the analysis purpose the load is applied at the side of the rivet holes. The loaded bracket is shown in fig. 3.1. The models and Von-mises stress contours for XII Cases are shown as follows.

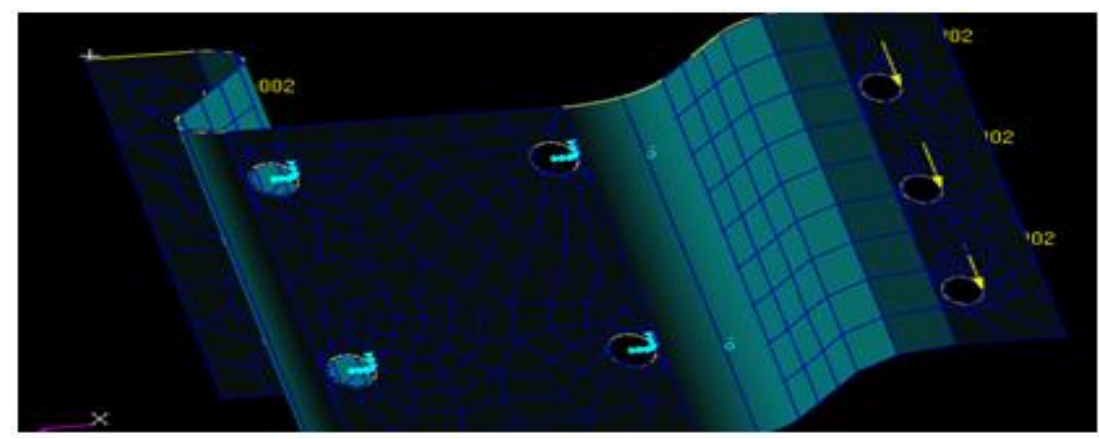

Fig. 3.1 Boundary constraints and loads on the bracket 

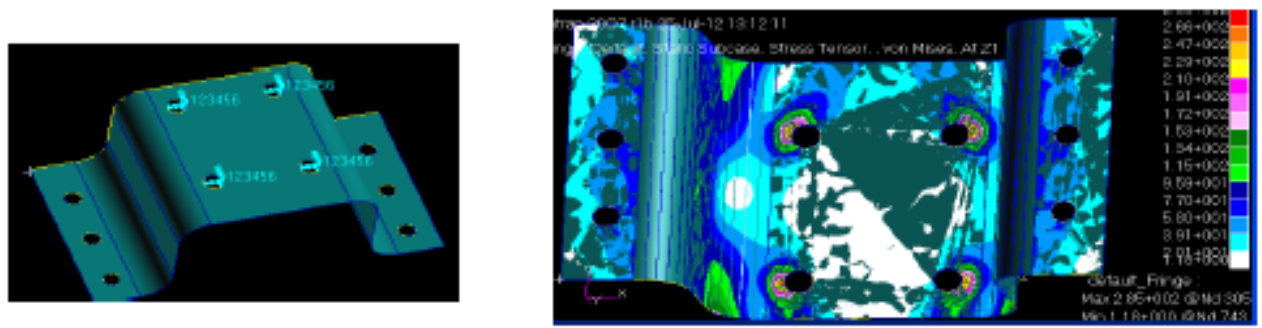

Fig.3.Bracket model without stiffener (CaseI) Fig.3.3 Von-mises stress contours-bracket without stiffener (CaseI)

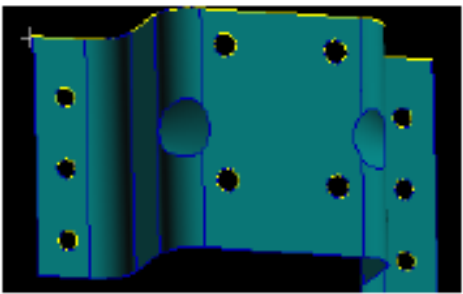

Fig.3.4 Bracket model with stiffeners (CaseII)

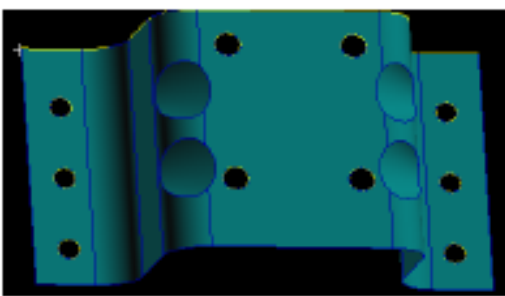

Fig.3.6Bracket with double stiffeners

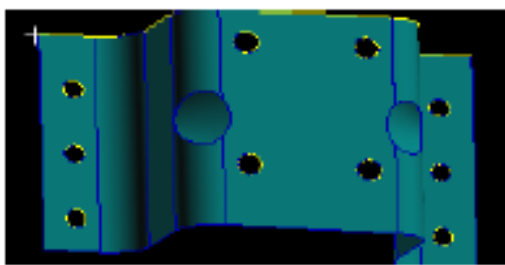

Fig.3.8Bracket-12 mm thickness (CaseIV)

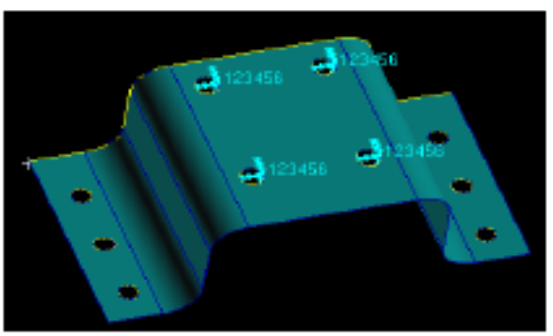

Fig. 3.10Bracket-12mm thick in ' $U$ 'profile (CaseV)

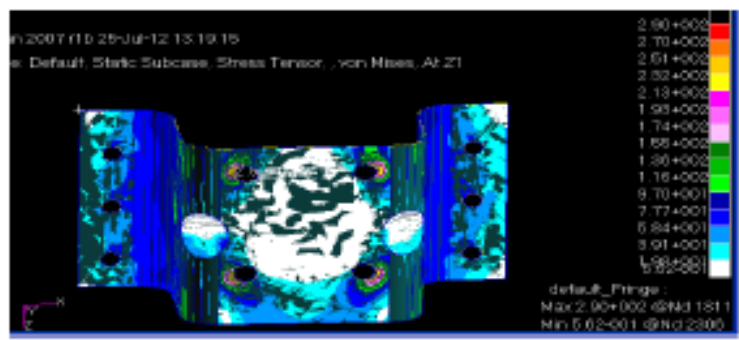

Fig.3.5 Von mises stress contours-bracket with stiffeners (CaseII)

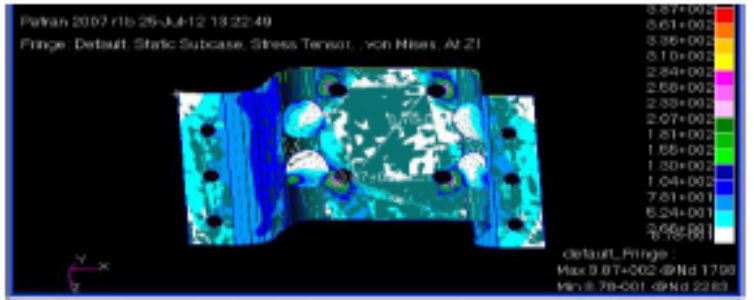

Fig.3.7Von mises stress contours- bracket with double stiffener(CaseIII)

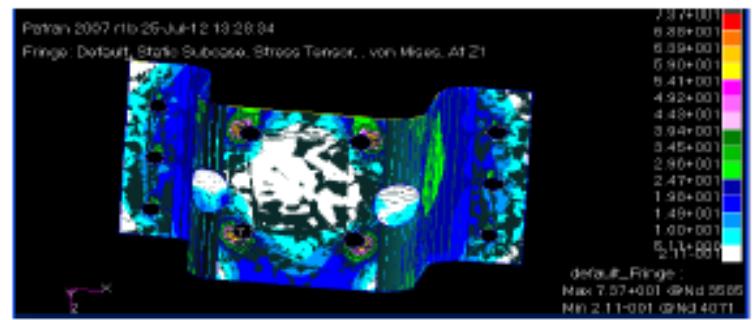

Fig.3.9 Von mises stress contours -bracket 12 mmthick(CaseIV)

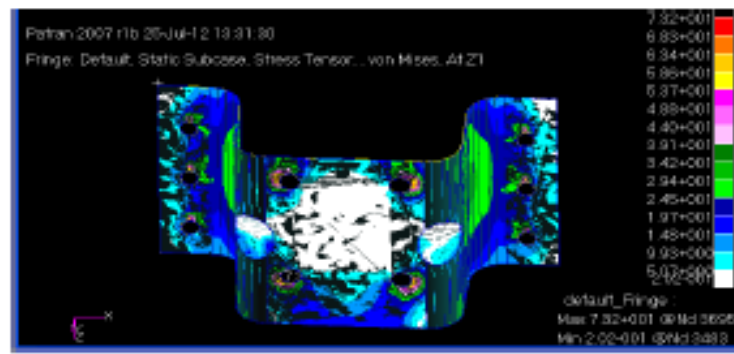

Fig.3.11Von-mises stress contours-bracket of $12 \mathrm{~mm}$ thickness in ' $U$ ' profile (CaseV) 


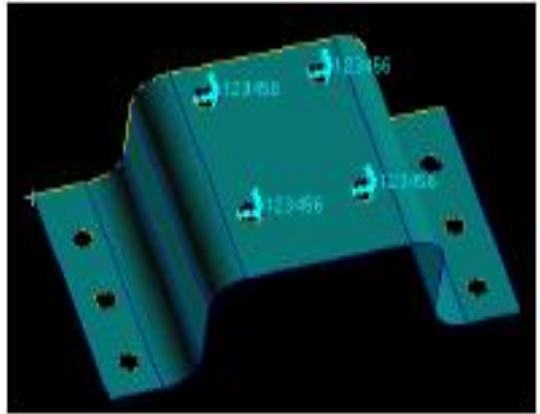

Fig.3.12Bracket-12 mm thick central plate(CaseVI)

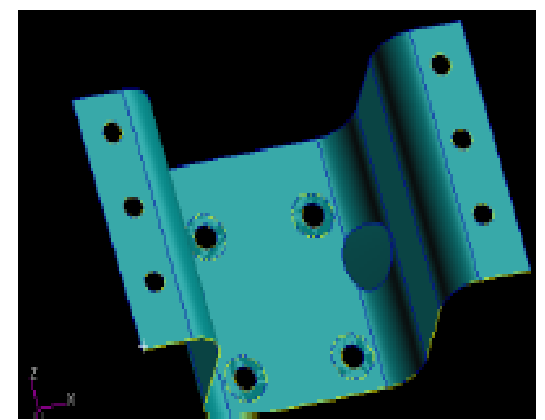

Fig.3.13Bracket with reinforced holes(CaseVII)

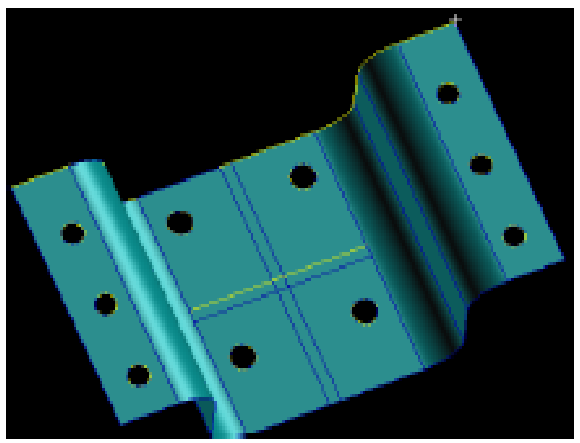

Fig. 3.15 Bracket model with two cross stiffeners (CaseVIII) Fig.3.16 Von-mises stress contours of bracket with

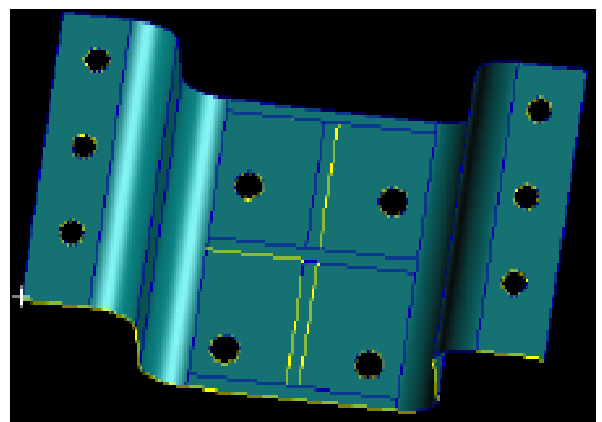

Fig.3.17 Bracket-two longitudinal and cross stiffeners(CaseIX) Fig.3.18 Von mises stress contours of bracket with two cross stiffeners (CaseVIII)

two longitudinal \& cross stiffeners (CaseIX)

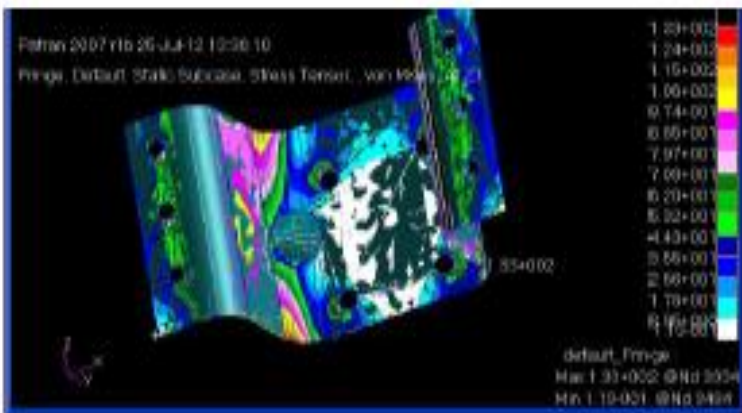

Fig.3.13 Von-mises stress contours of bracket-central plate of $12 \mathrm{~mm}$ thickness (CaseVI)

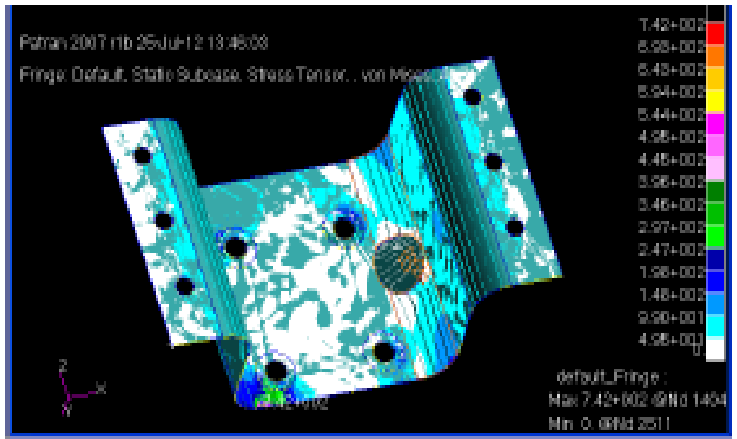

Fig. 3.14 Von-mises stress contours of bracket with reinforced holes (CaseVII)
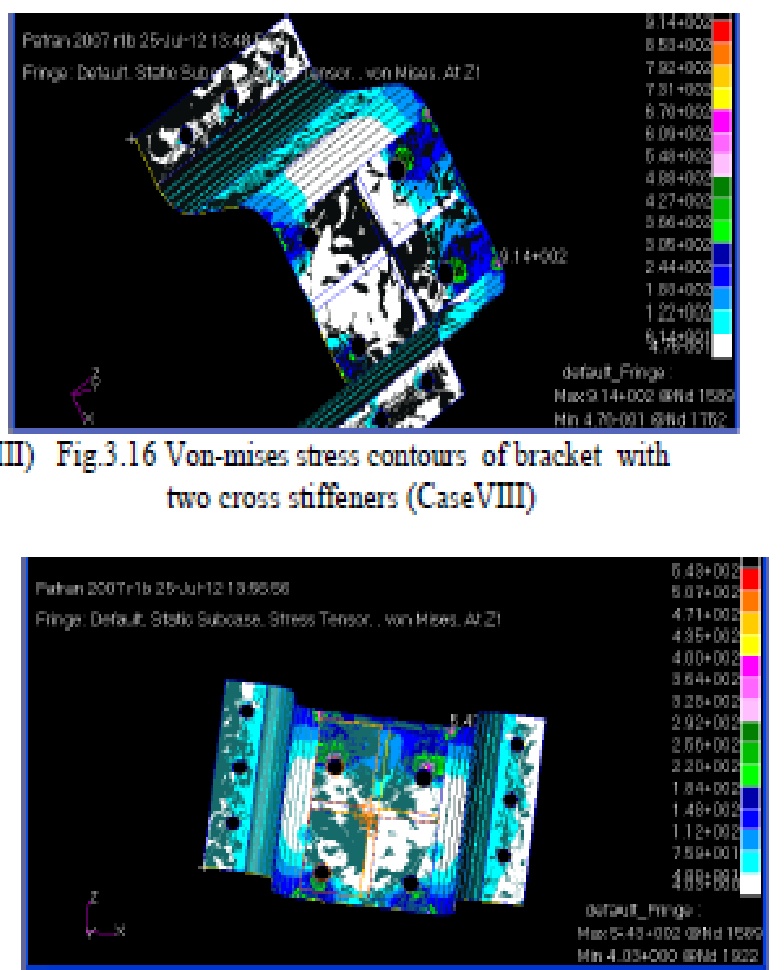


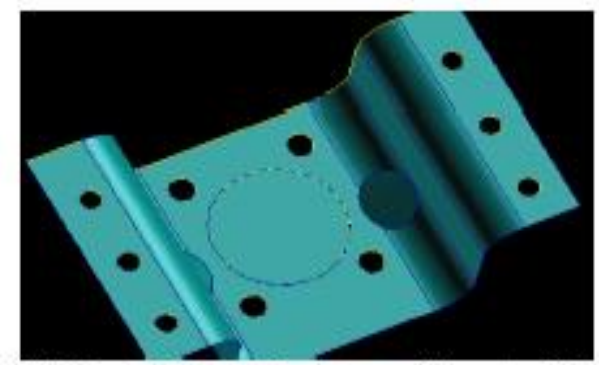

Fig.3.19 Central plate-circle depressed in centre(CaseX) ..

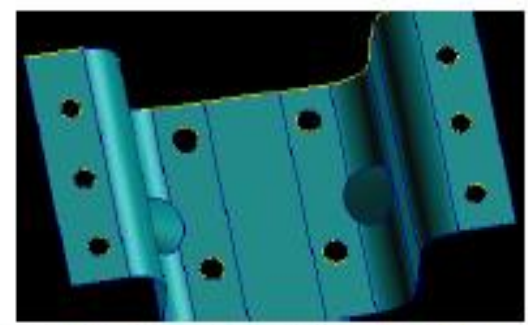

Fig. 3.21Bracket with traverse stiffeners (CaseXI)

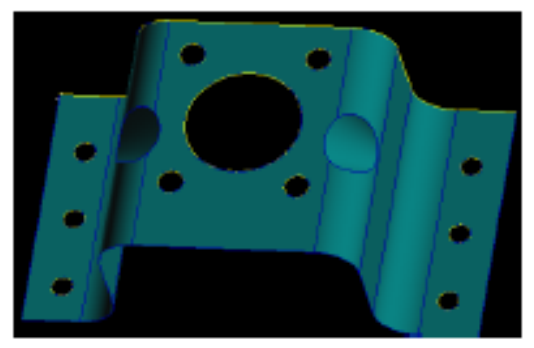

Fig.3.23 Bracket with circular hole in centre plate(CaseXII)

\section{IV.}

\section{RESULT, DISCUSSION AND CONCLUSION}

The results for various cases are compared in this section. Stress analysis of existing cross member bracket of the heavy truck chassis reveals that the stress level is up to $285 \mathrm{MPa}$ at the holes of the central plate which is fixed with the chassis. The remaining flange part of the bracket is under lesser stress levels. To reduce the weight of the bracket and also to achieve safe stress value various modifications are carried out in the existing bracket. Table 4.1 shows the results for the existing bracket and for the various modifications in it.

Table 4.1 Comparison of Result for Different Cases

\begin{tabular}{|l|l|l|l|c|}
\hline $\begin{array}{c}\text { Case } \\
\text { No. }\end{array}$ & Description & $\begin{array}{c}\text { Von mises stress } \\
\text { JIPa }\end{array}$ & $\begin{array}{c}\text { Max displacement } \\
\mathbf{m m}\end{array}$ & $\begin{array}{c}\text { Mass } \\
\mathrm{Kg}\end{array}$ \\
\hline I & Original bracket & 285.00 & 0.5340 & 2.28 \\
\hline II & With single stiffener & 290.00 & 0.5440 & 2.28 \\
\hline III & With double stiffener & 387.00 & 0.5800 & 2.28 \\
\hline IV & With double thickness & 73.70 & 0.0801 & 4.56 \\
\hline V & U plate thicker than flange (normal practice) & 73.20 & 0.0894 & 3.84 \\
\hline VI & With centre plate of 12mm thickness & 133.00 & 0.5630 & 2.89 \\
\hline VII & With reinforced holes & 742.00 & 0.6060 & 2.31 \\
\hline VIII & With cross stiffeners in central plate & 914.00 & 0.8520 & 2.34 \\
\hline IX & Longitudinal \& cross stiffeners in centre plate & 543.00 & 0.7120 & 2.47 \\
\hline X & Centre plate of 12mm thickness -depressed circle in centre & 133.00 & 0.5630 & 2.70 \\
\hline XI & Traverse stiffeners \& reinforced holes & 134.00 & 0.5640 & 2.64 \\
\hline XII & Centre plate of 12mm thickness with circular hole in centre & 133.00 & 0.5630 & 2.52 \\
\hline
\end{tabular}


From table 4.1 it has been found that the maximum stress present in the existing bracket is $285 \mathrm{MPa}$ and the bracket weight is $2.28 \mathrm{Kg}$. Under this stress level the failure of bracket is observed in practice. The stress level varies with different modifications and changes in design of existing design. Case I involves the original bracket. The incorporation of single or double stiffeners like the one in the original bracket, in Cases II, III does not show any improvement in stress level. In Cases IV to VII thickness of the plate is increased at different locations. In Cases IV, V and VI stress is reduced upto $73.20 \mathrm{MPa}$ while weight was reduced upto 2.89 $\mathrm{Kg}$. In Case $\mathrm{V}$ which is the normal practice in repair industry, the stress is lowest at $73.20 \mathrm{MPa}$ but at the expense of material as the bracket weight is higher at $3.84 \mathrm{Kg}$. It is observed that this bracket is safe in practice. The resuppliers of the bracket in the open market viz; Dyna etc, have tried to effect this by adding an extra 6 $\mathrm{mm}$ thickness plate welded along the failure region.

As seen from table 4.1 Case XII leads to maximum weight reduction and the bracket weighs $2.52 \mathrm{Kg}$, which is only $10 \%$ more than the original bracket, which is marginal and the stress is at a safe level of 133 $\mathrm{MPa}$. Thus, the modification in Case XII is recommended.

Further the actual loading condition would have additional load due to, additional momentary force on bracket in impacts and lateral tensile pull due to chassis flab, alignment errors, jumping of wheel, etc. All these factor shall contribute to increase in the load and hence the stresses.

\section{ACKNOWLEDGEMENT}

Special thanks to Er.Balvindersingh J. Guron of JST, transporters for BILT and Ultratech Cements

\section{REFERENCES}

[1] Mantere, Adams, "Finite element analysis based design of cross member beam for heavy truck". MSc programmes in Engineering, Lulea university, ISSN, pages 1402-1667, 2003.

[2] Daniel Grieb and Zayar Thein, "Stress and Stiffness of a Frame", Finite Element Simulation in Design, Chalmers University of Technology, Group G08, 2009 (website resource).

[3] P.V.S.C.S Varma, V.V.Katkar, Ranjit Babar, “ Optimization of a Bus Chassis using Hypermorph and Hyperstudy ", Tata Motors, ERC-CAD, Pimpri, Pune (website resource)

[4] Abd Rehman, Mohd.Nasir Tamin, Ojo Kurdi, " Stress analysis of a heavy duty truck chassis using FEM ", faculty of mechanical engineering, University of Technology, Malaysia. ( website resource ).

[5] S.S.Sane, Ghanshyam Jadhav, "Stress analysis of light commercial vehicle chassis by FEM ", Piaggio Vehicles Private Limited, Pune (website resource)

[6] Ashutosh Dubey, Vivek Dwivedi, “Vehicle chassis analysis : load cases and boundary conditions for stress analysis" ( website resource ).

[7] N.K.Ingole, Dr. D.V. Bhope, “ Stress Analysis of Tractor Trailer Chassis for Self Weight Reduction ”, IJEST, VOLUME 3, ISSUE 9, pages 7218-7225, Sept.2011.

[8] Cicek Karao lu, N. Sefa Kuralay, " Stress Analysis of Truck Chassis with Riveted Joints Using FEM, Elements in Analysis and Design, Volume 38, Issue 12, Pages 1115 - 1130, October 2002

[9] Dyna Engineering Works, khatia, (website resource), www.indiamart.com dengineeringworks

[10] Finite Elements, www.book.google.co.in, vol 30, issue 12, pages 1115-1130 , 2002 